\title{
Health-related quality of life of HIV patients with and without tuberculosis registered in a Tertiary Hospital in Port Harcourt, Nigeria
}

\author{
Njideka E. Kanu ${ }^{1,2}$, Charles I. Tobin-West ${ }^{3}$ \\ ${ }^{1}$ Department of Community Medicine, University of Medical Sciences, Ondo, Nigeria \\ ${ }^{2}$ Nigeria Field Epidemiology and Laboratory Training Program, Abuja, Nigeria \\ ${ }^{3}$ College of Health Sciences, University of Port Harcourt, Port Harcourt, Nigeria
}

\begin{abstract}
Introduction: Little is known about health-related quality of life (HRQOL) of patients who suffer from human immunodeficiency virus (HIV)/tuberculosis (TB) in Nigeria. This study was carried out to measure and compare the HRQOL of HIV patients with and without TB at the HIV Clinic of University of Port Harcourt Teaching Hospital, Port Harcourt, Nigeria.

Material and methods: A comparative cross-sectional study design and simple random sampling was used to recruit $144 \mathrm{HIV}$ patients with TB and $144 \mathrm{HIV}$ patients without TB. Information were collected on socio-demographic and socioeconomic variables, while their HRQOL was measured using the 26-item World Health Organization Quality of Life instrument. Univariate and bivariate analysis was carried out in Epi-info 7.

Results: Females constituted 52\% and 56\% of HIV-only and HIV/TB co-infected groups, respectively. Their mean ages were $36.03 \pm 10.92$ and $35.69 \pm 10.28$ years, respectively $(p=0.532)$. HRQOL score ranged from 61.9 to 78.5 for HIV patients, and 61.6 to 75.8 for the co-infected patients. Co-infected patients had lower HRQOL in the physical $(p=0.016)$, psychological $(p=0.006)$, and global $(p=0.029)$ domains of HRQOL than HIV-only patients. The two groups did not differ significantly in the social and environmental domains $(p>0.05)$.

Conclusions: The co-morbidity condition of HIV/TB significantly lowers the quality of life of sufferers. Attention should be focused on the medical and psychological management of HIV/TB co-infected patients in order to enhance their QOL.
\end{abstract}

HIV AIDS Rev 2018; 17, 3: 210-217

DOI: https://doi.org/10.5114/hivar.2018.78494

Key words: HIV, Nigeria, health-related quality of life, HIV/TB, Port Harcourt.

\section{Introduction}

The human immunodeficiency virus (HIV) infection causes a chronic and debilitating disease of global public health concern. The pandemic has caused millions of deaths worldwide and has crippled the lives of many more [1, 2]. Sub-Saharan Africa is the most affected region, with nearly sixty-nine percent of all people living with HIV inhabiting the region [3]. Nigeria bears a huge burden of the epidemic, with an estimated 3.1 million people living with HIV in 2011 [4].

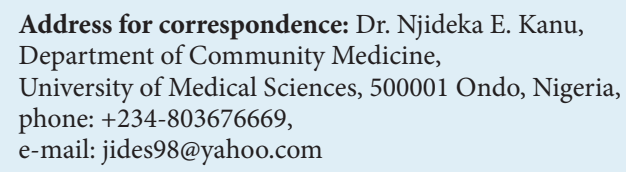

Article history:

Received: 17.08.2017

Received in revised form: 01.03.2018

Accepted: 02.03.2018

Available online: 15.08.2018
International Journal of HIV-Related Problems

HIV \& AIDS

R e vi e w 
It ranks as one of the countries with the highest burden of HIV infection in the world, next to India and South Africa [4]. Almost 28 years after the first acquired immune deficiency syndrome (AIDS) case reported in Nigeria, the country still faces epidemics, and the majority of HIV/AIDS patients continue to suffer with the debilitating effect of the disease, with a serious impact on their quality of life [5]. The impact of tuberculosis (TB) on the lives of HIV patients cannot be overemphasized. TB remains the leading cause of death among people living with HIV $[2,6]$. People living with HIV and infected with TB are 30 times more likely to develop active TB disease than people without HIV. At least a third of people living with HIV worldwide are infected with the tuberculosis bacteria [7], with HIV and TB forming a lethal combination, each speeding the other's progress. The World Health Organization's Quality of Life (WHOQOL) group has defined quality of life (QOL) as individuals' perception of their position in life in the context of the culture and value systems, in which they live and in relation to their goals, expectations, standards, and concerns [8]. The term 'healthrelated quality of life' (HRQOL) is a multi-dimensional construct referring to patients' perceptions of the impact of disease and treatment on their physical, psychological, social function, and wellbeing. QOL encompasses the concept of HRQOL and other domains such as environment, family, and work. When quality of life is considered in the context of health and disease, it is commonly referred to as health-related quality of life. The effect of HIV and AIDS on an individual goes beyond the physical symptoms and signs. It is a disease that is highly associated with stigma and discrimination, and is known to also affect the psychological, social, spiritual life as well as other aspects of the patients' life $[9,10]$. It thus impairs the quality of life. Many HIV patients battle numerous social problems such as stigma and depression, which affect their quality of life, in terms of their physical, mental, and social health $[1,5]$. HIV and HIV/TB co-infection are associated with stigma, resulting in patients being rejected by their families, their communities, at their places of work, and are seen as unfit for work. In addition, health workers' attitude could lead to mental stress and reduction in QOL [11].

One of the aims of HIV/AIDS therapy is to improve the wellbeing and quality of life of affected people. The introduction of highly active antiretroviral therapy (HAART) has led to a marked reduction in AIDS-related morbidity and mortality [12]. Although the patients live longer, their quality of life is usually severely compromised. HIV and HIV/TB co-infected patients often suffer from intense social stigma, which forces them to change jobs or places of living, putting further stress on the already weak economic situation [13]. They experience discrimination and/or misunderstanding, tend to become isolated and lose social support from persons significant to them [14]. These often compromise their quality of life. With the appreciable rise in longevity of people living with HIV and AIDS (PLWHA), it is important to improve their quality of life [15]. HIV/AIDS and tuberculosis have such serious repercussions on psychic, social, and physical well-being of the infected, that the assessment of their HRQOL will help in measuring how these people are re-integrated into the society after the initial health crisis they faced on diagnosis of the disease. There is limited evidence in Nigeria on how PLWHA perceive their quality of life in the face of HIV/TB co-infection. Therefore, it is imperative to understand these issues in order to evaluate the impact of the disease on patients' health outcomes.

The aim of this study was to measure and compare health-related quality of life of adult patients with HIV/ AIDS with those with HIV/TB co-infection. This was to provide information on the management of these two conditions for better treatment adherence and outcomes. It was also aimed at contributing to health systems strengthening by having patient centered healthcare services.

\section{Material and methods}

\section{Study area}

The study was carried out in the HIV clinic of the University of Port Harcourt Teaching Hospital (UPTH), Rivers state, Nigeria. Rivers state has one of the highest prevalence rates of HIV/AIDS in Nigeria, with a prevalence of $15.2 \%$ [16]. The state has a total population of 5.18 million, with an annual growth rate of $3.0 \%$. The state is cosmopolitan and is home to all ethnic groups in Nigeria and foreigners. It is also an economic hub in Nigeria because of its abundant natural resources of oil and gas. The economic importance of the state makes it attractive to people from all works of life, searching for economic opportunities. Rivers state has a health care system at tertiary, secondary, and primary levels. The health care system is a combination of public and private sector. There are two tertiary hospitals, and several secondary and primary centers fairly distributed all over the state. Nevertheless, the health care system is generally weak and plagued by acute shortage of essential medicines and supplies, poor infrastructure, and human resources.

\section{Study setting}

The University of Port Harcourt Teaching Hospital is 800 bed tertiary institution, owned and managed by the Federal government of Nigeria. It serves as a referral hospital to all secondary and primary health facilities in Rivers State and neighbouring Abia, Akwa Ibom, Bayelsa, and Imo states. The HIV clinic has close to 12,000 registered HIV/AIDS patients, out of which about 5,300 are on antiretroviral treatment (ART). It is one of the six health facilities caring for HIV/AIDS patients in the state. The clinic attends to an average of 60-100 HIV patients daily, with over $50 \%$ of these patients coinfected with TB. The ARV Clinic is supported by a grant from the Family Health International (FHI-360) under the American President's Emergency Plan for AIDS Relief (PEPFAR) Initiative to implement its diverse activities. All HIV-positive patients received in the ARV 
clinic are screened for $\mathrm{TB}$, and those diagnosed with active $\mathrm{TB}$ are enrolled in the directly observed treatment short course (DOTS) programme for the management of TB. Similarly, all TB suspects/patients are offered HIV counselling and testing, and if confirmed positive, they receive HIV/AIDS care. This two-way referral is in accordance with the Nigeria National Tuberculosis and Leprosy Control Program (NTBLCP) guidelines for treatment and control of HIV/TB in Nigeria [6].

\section{Study design and population}

The study was a comparative, cross-sectional investigation of health-related quality of life of HIV/AIDS patients, and those with HIV/AIDS and TB co-infection, carried out among adult patients 18 years and above, diagnosed with HIV/AIDS, with or without TB co-infection, attending the HIV clinic in the University of Port Harcourt Teaching Hospital, Rivers state.

\section{Inclusion and exclusion criteria}

All adult HIV patients 18 years and above with or without TB co-infection and patients with confirmed HIV-positive status who had received antiretroviral drugs for at least a month prior to the study (this was to allow adequate time for patients to adapt to the drugs) were included in the study. HIV-positive patients who were yet to commence ART or had been on therapy for less than 1 month before the study were excluded due to possibility of not adequately adapted to the antiretroviral drugs. Pregnant women, terminally ill/debilitated patients, including patients on admission as well as patients with other co-morbidities were also excluded, except for the comparison group of HIV/AIDS and TB co-infection.

\section{Sample size determination}

The formula for calculating sample size to determine the difference between 2 proportions was employed as follows:

$$
n=(\mathrm{u}+\mathrm{v}) 2[(\mathrm{p} 1(100-\mathrm{p} 1)+\mathrm{p} 2(100-\mathrm{p} 2)] /(\mathrm{p} 1-\mathrm{p} 2)
$$

where $n$ - minimum sample size for each group; $u$ - power at $90 \%=1.28 ; v-$ significance level at $5 \%=1.96 ; p 1-$ proportions of HIV/AIDS patient assumed to have good HRQOL $=50.38 \%$ (derived from a previous study) [17]; $p 2$ - proportions of patients with HIV/AIDS and TB co-infection with good HRQOL $=30.97 \%$ (derived from the same study) [17]; non-response rate of $10 \%$. Minimum sample size $(n)$ was 144 patients per group.

\section{Sampling technique}

Recruitment of participants was by simple random sampling. The list of registered HIV patients presenting daily for treatment in the clinic was obtained from the medical records staff. Numbers were assigned to each patient. Using a table of random numbers, $3 \mathrm{HIV}$ patients and $3 \mathrm{HIV} / \mathrm{TB}$ co-infected patients were randomly selected and interviewed daily in order to broaden the scope of the sample.

\section{Study instruments}

A structured interviewer-administered questionnaire with the WHOQOL-BREF was adapted from WHOQOL group and used to collect information from the respondents. The questionnaire consisted of questions of sociodemographic details, socio-economic characteristics, and WHO quality of life (WHOQOL-BREF) assessment [18]. The WHOQOL-BREF is a 26 -item generic questionnaire, a short version of the WHOQOL-100 assessment [19]. It measures four broad domains such as: physical health, psychological well-being, social relations, and environment [8]. Physical health domain comprises of 7 items that assess areas such as the presence of pain and discomfort, dependence on substances or treatments, energy and fatigue, mobility, sleep and rest, activities of daily living, and perceived working capacity. Psychological well-being comprises of 6 items that assess areas such as patient's affect, both positive and negative, self-concept, higher cognitive functions, body image and spirituality. Social relationship assesses areas such as social contacts, family support, ability to care for family, and sexual activity. Environmental domain comprises of 8 items that assess aspects such as freedom, quality of home environment, physical safety, security and financial status, involvement in recreational activity, health and social care as applicable to the quality and accessibility thereof. There are two other items that were measured separately: (1) patient's overall perception of QOL, and (2) overall perception of his/her health. Each item was categorized into a five-point Likert's scale ranging from 1-5, with 1 being the lowest possible state and 5 being the highest. Domain scores are scaled in a positive direction; higher scores denote higher QOL. The mean score of items within each domain was used to calculate the domain scores compatible with the scores used in WHOQOL-100 and subsequently transformed into a 0-100 scale [20]. This instrument has been reported to be convenient, reliable, and valid for the use in large research studies. It has also been translated into different languages, including indigenous languages like Hausa and Yoruba, and used in different cultural settings yielding comparable scores across different languages and cultures [21, 22]. The WHOQOL-BREF has been well validated for measuring quality of life in people living with AIDS elsewhere in Nigeria and abroad with satisfactory results $[15,23-25]$.

\section{Data collection methods}

Three research assistants were trained to administer the questionnaires to the patients daily over a period of 3 months. 
Table 1. Socio-demographic characteristics of study participants

\begin{tabular}{|c|c|c|c|c|}
\hline Variables & HIV, $n=144$ (\%) & HIV $/$ TB, $n=144(\%)$ & $x^{2}$ & $p$-value \\
\hline \multicolumn{5}{|l|}{ Age group (years) } \\
\hline$\leq 24$ & $12(8.3)$ & $18(12.5)$ & \multirow{6}{*}{3.157} & \multirow{6}{*}{0.532} \\
\hline $25-34$ & $66(45.8)$ & $54(37.5)$ & & \\
\hline $35-44$ & $37(25.7)$ & $41(28.5)$ & & \\
\hline $45-54$ & $22(15.3)$ & $21(15.6)$ & & \\
\hline$\geq 55$ & $7(4.9)$ & $10(6.9)$ & & \\
\hline Mean age & $35.69 \pm 10.28$ & $36.03 \pm 10.92$ & & \\
\hline \multicolumn{5}{|l|}{ Sex } \\
\hline Male & $69(47.9)$ & $63(43.8)$ & \multirow{2}{*}{0.503} & \multirow{2}{*}{0.478} \\
\hline Female & $75(52.1)$ & $81(56.3)$ & & \\
\hline \multicolumn{5}{|l|}{ Marital status } \\
\hline Single & $66(45.8)$ & $70(48.6)$ & \multirow{4}{*}{0.488} & \multirow{4}{*}{$0.922^{*}$} \\
\hline Married & $62(43.1)$ & $58(40.3)$ & & \\
\hline Separated/divorced & $3(2.1)$ & $2(1.4)$ & & \\
\hline Widowed & $13(9.0)$ & $14(9.7)$ & & \\
\hline \multicolumn{5}{|l|}{ Ethnicity } \\
\hline Igbo & $52(36.1)$ & $68(47.2)$ & \multirow{6}{*}{8.229} & \multirow{6}{*}{$0.144^{*}$} \\
\hline Ikwere & $24(16.7)$ & $23(16.0)$ & & \\
\hline ljaw & $19(13.2)$ & $14(9.7)$ & & \\
\hline Yoruba & $9(6.3)$ & $2(1.4)$ & & \\
\hline Hausa & $3(2.1)$ & $5(3.5)$ & & \\
\hline Others & $37(25.7)$ & $32(22.2)$ & & \\
\hline \multicolumn{5}{|l|}{ Religion } \\
\hline Christianity & $133(92.4)$ & $136(94.4)$ & \multirow{3}{*}{3.033} & \multirow{3}{*}{$0.386^{\star}$} \\
\hline Islam & $10(6.9)$ & $5(3.5)$ & & \\
\hline Traditional religion & $1(0.7)$ & $2(1.4)$ & & \\
\hline \multicolumn{5}{|l|}{ Family type } \\
\hline Monogamous & $114(79.2)$ & $111(77.1)$ & \multirow{2}{*}{0.183} & \multirow{2}{*}{0.183} \\
\hline Polygamous & $30(20.8)$ & $33(22.9)$ & & \\
\hline \multicolumn{5}{|l|}{ Household size } \\
\hline$\leq 4$ & $53(36.8)$ & $61(42.4)$ & \multirow[t]{2}{*}{0.929} & \multirow[t]{2}{*}{0.335} \\
\hline$>4$ & $91(63.2)$ & $83(57.6)$ & & \\
\hline Mean household size & $5.96 \pm 4.0$ & $5.88 \pm 3.93$ & & $0.16^{\star *}$ \\
\hline
\end{tabular}

HIV - human immunodeficiency virus, TB - tuberculosis

${ }^{*}$ Fisher's exact $p$-value, ${ }^{* *}$ t-test

\section{Data analysis}

Data were analyzed using SPSS version 19 statistical software. Demographic and socioeconomic factors were presented with frequency tables. Domain scores were manually calculated, entered, and cross-checked for accuracy with a computer. The HRQOL was interpreted using the mean values as the cut off for data that were normally distributed and the median values for data that were skewed. Values below the mean/median scores were graded as poor, while those above the mean or median were graded as good [20]. Means and standard de- viations were calculated for continuous variables, the independent student's $t$-test was used to compare differences between mean scores. The $\mathrm{c}^{2}$ test was used to examine the associations between quality of life and HIV status. A p-value of 0.05 was considered statistically significant.

\section{Ethical consideration}

Ethical approval for the study was obtained from the Research Ethics Committee of the University of Port Harcourt Teaching Hospital; UPTH/ADM/90/SJI/VOL.XI/34. 
Table 2. Mean score of health-related quality of life (HRQOL) dimensions of participants

\begin{tabular}{l|c|c|c|c}
\hline HRQOL dimensions & $\begin{array}{c}\text { HIV } \\
\text { Mean } \pm \text { SD }\end{array}$ & $\begin{array}{c}\text { HIV/TB } \\
\text { Mean } \pm \text { SD }\end{array}$ & t-test & $\begin{array}{c}\text { Students } t \text {-test } \\
p \text {-value }\end{array}$ \\
\hline Self-rated QOL & $78.47 \pm 17.39$ & $75.83 \pm 18.15$ & 1.26 & 0.209 \\
\hline Satisfaction with health & $76.67 \pm 19.50$ & $75.56 \pm 17.45$ & 0.51 & 0.611 \\
\hline Physical health & $74.82 \pm 16.19$ & $70.01 \pm 17.52$ & 2.42 & $0.016^{*}$ \\
\hline Psychological health & $71.09 \pm 11.97$ & $67.13 \pm 12.15$ & 2.79 & $0.006^{*}$ \\
\hline Social relationship & $65.28 \pm 24.40$ & $61.63 \pm 27.19$ & 1.20 & 0.232 \\
\hline Environmental & $61.89 \pm 14.28$ & $60.20 \pm 14.31$ & 1.00 & 0.316 \\
\hline Global domain & $68.27 \pm 12.99$ & $64.74 \pm 14.36$ & 2.19 & $0.029^{*}$ \\
\hline
\end{tabular}

HIV - human immunodeficiency virus, TB - tuberculosis

*Statistically significant

The aim and objectives of the study were explained to the members of staff of the ARV clinic, and written informed consent was obtained from each participant before the interview. All study participants were informed of the benefits of the study and assured of their confidentiality.

\section{Results}

\section{Socio-demographic characteristics of study participants}

A total of 144 HIV/AIDS patients without TB and 144 HIV/AIDS co-infected with TB were recruited for the study. The study consisted of 156 (54.2\%) females and 132 (45.8\%) males. The mean age of patients without TB was 35.69 \pm 10.28 years and those co-infected with $\mathrm{TB}$ was 36.03 \pm 10.92 years. The majority of the patients, 66 (45.8\%) fell within the age category of 25-34 years among those HIV only and $54(37.5 \%)$ among those co-infected with TB. The patients with HIV-only were mainly single 66 (45.8\%), of the Igbo ethnic group 52 (36.1\%), and live in large households above 4 members 91 (63.2\%). Those with TB co-infection had similar characteristics with the majority also single, 70 (48.6\%), Igbo 68 (47.2\%), and living in large family settings 83 (57.6\%). There was no significant difference in demographic characteristics in both groups (Table 1).

\section{Health-related quality of life of HIV- only and HIV/TB co-infected patients}

The highest mean score for HRQOL among HIV-only patients was self-rated health $(78.47 \pm 17.39)$, while the lowest score was in the environmental $(61.89 \pm 14.28)$ domains. The highest and lowest mean scores for HRQOL among co-infected patients followed similar pattern of self-rated health $(75.83 \pm 18.15)$, and environmental health (60.20 \pm 14.31 ), respectively (Table 2 ).

The global mean rating of QOL for HIV patients without TB $(68.27 \pm 12.99)$ and those co-infected with TB (64.74 \pm 14.36 ) were significantly different $(t$-test $=2.19 ; p=0.029$ ). The co-infected patients had poorer mean scores of QOL in their physical health ( $t$-test $=2.42 ; p=0.016)$ and in their psychological health $(t$-test $=2.79 ; p=0.006)$ than the HIV-only patients. Other dimensions of quality of life, like the self-rated health, satisfaction with health, social relationship and environmental health were similar in both groups $(p>0.05)$ (Table 2).

\section{The relationship between HIV, tuberculosis, and quality of life of patients}

Three quarters, 109 (75.7\%) of HIV patients (without TB) were satisfied with their health, and $104(72.2 \%)$ rated their health status as good. In all, more than half of them had good QOL in the physical, psychological, environmental, social relationship, and global domains. Similarly, 106 (73.6\%) of the HIV patients co-infected with TB were also satisfied with their health, and $100(69.4 \%)$ rated their health as good. Nevertheless, less than half of the patients co-infected with TB had good QOL in the physical 68 (47.2\%), psychological $71(49.3 \%)$, social relationship 66 (48.5\%), environment 68 (47.2\%), and global aspects 69 (48.9\%). The proportion of patients with good QOL was significantly higher in the HIV group than in the group co-infected with TB. This was also more pronounced in the physical health $\left(\chi^{2}=4.030\right.$; $p=0.045)$ and psychological health domains $\left(\chi^{2}=5.644\right.$; $p=0.018)$ (Table 3$)$.

\section{Discussion}

The overall mean score of QOL of the HIV patients with and without TB co-infection was appreciable, which is a good sign for case management and treatment outcomes. The result might signify a general sense of well-being among the patients, including aspects of happiness and satisfaction with life as a whole, and services received at the facility. The highest scores were in the physical and psychological health domains, and slightly lower scores were seen in social relationship and environmental health. These findings were similar to results obtained in comparable studies carried out in Kogi [23], Kwara [24], and South West Nigeria [25] but 
Table 3. The relationship between human immunodeficiency virus (HIV), tuberculosis (TB), and quality of life (QOL) of patients

\begin{tabular}{|c|c|c|c|c|}
\hline & \multicolumn{2}{|c|}{ Health-related quality of life } & \multirow{2}{*}{$x^{2}$} & \multirow{2}{*}{$p$-value } \\
\hline & Good, $n$ (\%) & Poor, $n(\%)$ & & \\
\hline \multicolumn{5}{|c|}{ Self-rated QOL } \\
\hline HIV & $104(72.2)$ & $40(27.8)$ & \multirow[t]{2}{*}{0.269} & \multirow[t]{2}{*}{0.604} \\
\hline HIV/TB & $100(69.4)$ & $44(30.6)$ & & \\
\hline \multicolumn{5}{|c|}{ Satisfaction with health } \\
\hline HIV & $109(75.7)$ & $35(24.3)$ & \multirow[t]{2}{*}{0.165} & \multirow[t]{2}{*}{0.684} \\
\hline $\mathrm{HIV} / \mathrm{TB}$ & $106(73.6)$ & $38(26.4)$ & & \\
\hline \multicolumn{5}{|c|}{ Physical health } \\
\hline HIV & $85(59.0)$ & $59(41.0)$ & \multirow[t]{2}{*}{4.030} & \multirow[t]{2}{*}{$0.045^{*}$} \\
\hline $\mathrm{HIV} / \mathrm{TB}$ & $68(47.2)$ & $76(52.8)$ & & \\
\hline \multicolumn{5}{|c|}{ Psychological health } \\
\hline HIV & $91(63.2)$ & $53(36.8)$ & \multirow[t]{2}{*}{5.644} & \multirow[t]{2}{*}{$0.018^{*}$} \\
\hline $\mathrm{HIV} / \mathrm{TB}$ & $71(49.3)$ & $73(50.7)$ & & \\
\hline \multicolumn{5}{|c|}{ Social relationship } \\
\hline HIV & 69 (51.9) & $65(48.1)$ & \multirow[t]{2}{*}{0.308} & \multirow[t]{2}{*}{0.579} \\
\hline $\mathrm{HIV} / \mathrm{TB}$ & $66(48.5)$ & $74(51.5)$ & & \\
\hline \multicolumn{5}{|c|}{ Environmental } \\
\hline HIV & $80(55.6)$ & $64(44.4)$ & \multirow[t]{2}{*}{2.002} & \multirow[t]{2}{*}{0.157} \\
\hline $\mathrm{HIV} / \mathrm{TB}$ & $68(47.2)$ & $76(52.8)$ & & \\
\hline \multicolumn{5}{|c|}{ Global domain } \\
\hline HIV & $86(59.0)$ & $58(41.0)$ & \multirow[t]{2}{*}{2.349} & \multirow[t]{2}{*}{0.091} \\
\hline HIV/TB & 69 (48.9) & 75 (51.1) & & \\
\hline
\end{tabular}

*Statistically significant

significantly at variance from what was obtained in Ghana [26] and Nepal [27], where the lowest scores were in the psychological domain. The good scores in the physical and psychological health in this study may be partially linked with health workers' comprehensive and consistent counseling on medication adherence as well as patients' overall education on the nature and course of the diseases. It may also be a sign that the various intervention efforts aimed at dispelling myths and misconceptions about HIV and TB as well as discouraging stigma and discrimination are beginning to yield expected tangible results.

On the other hand, the lower mean score in the social relationship domain could be attributed to persisting pockets of social stigma and discrimination, including self-stigmatization, which is a predominant feature among PLWHA. Stigma and discrimination have been shown to be major barriers to treatment uptake and adherence, and can significantly reduce patient's QOL [28]. In a Northern Ethiopian study, high perceived stigma was strongly associated with poor psychological quality of life [29]. The aftermath of such result is a negative impact on patients' family and personal lives, including sexual relationships. This finding corroborates the results of similar studies in Ibadan, Nigeria [15] but disagrees with results from India [13] and
Sao Paulo, Brazil [30], where the mean score was highest in the social relationship. This latter result may be suggestive of better societal support and care for PLWHA in these communities.

In comparing the Global mean rating of QOL for HIV patients with and without co-infection, significant differences were observed. These were also in relation to the physical and psychological health of the patients, but no difference was found between the two groups in social relationship and environmental health domains. HIV patients without TB had significantly higher QOL mean scores than those co-infected with TB in the physical, psychological, and overall QOL. The result is in agreement with that of a study conducted in South-West Nigeria, which reported that participants with HIV/TB co-infected patients had significantly lower QOL in the physical, psychological, and independence domains, when compared with HIV patients without TB [25]. The finding is also in agreement with another study conducted in Ethiopia, which found that HIV/ TB co-infected patients had a lower quality of life in all aspects as compared to HIV-infected patients without active TB [17]. However, there was no significant differences in mean scores in the social relationship and environment domains between HIV patients and HIV/TB co-infect- 
ed patients, unlike the report by the Ethiopian study [17]. It is believed that the occurrence of two stigmatizing diseases like HIV and TB can synergistically impact negatively on the QOL of the patients. Such patients are more likely to be depressed, and less likely to have close partner support and sexual relationships. Recent studies have shown that high proportion of HIV patients tend to suffer depression, and the diagnosis of depression is a significant predictor of poor QOL $[31,32]$. The duo of depression and lack of family support have also been found to be associated with poor QOL among co-infected patients [17]. According to Akpa et al. [33], people from families affected by HIV/AIDS had significantly poorer quality of life than those from families not affected by HIV. Family and social support may therefore play a role in improving QOL of HIV sufferers.

The mean scores for self-rated health and satisfaction with health in both groups were high, which may be attributed to their positive outlook to life as a result of frequent and consistent counseling programme under the elaborate HIV control programme in the facility. The programme strategy also includes counseling on the effects of diagnosis and treatment, quality and length of life, and positive living, so that patients are able to adjust better psychologically and socially.

\section{Limitations}

Using client self-report as a measure of QOL is limited by recall bias and an increased likelihood that study participants may overestimate or underestimate their QOL. Nevertheless, it has been shown that self-assessed health status provides a more powerful predictor of mortality and morbidity than many objective measures of health [34]. To minimize this limitation, the study participants were had enough time to respond to questions and to refresh their memories. Where questions were not clearly understood, they were explained in Pidgin English, which is widely understood and spoken in Rivers state.

\section{Conclusions}

The co-infection of HIV and TB impacts negatively on the health and well-being of the sufferers, significantly lowering their quality of life. Therefore, more attention should be devoted to the medical management of such co-morbid patients to improve their physical health. There is also a need to incorporate mental health services and scale up psycho-social support for such patients and their treatment supporters, in order to minimize their stigmatization and rejection as well as to improve their self-worth and positive attitude outlook to life.

\section{Conflict of interest}

The authors declare no potential conflicts of interest with respect to the research, authorship, and/or publication of this article.

\section{References}

1. Joint United Nations Programme on HIV/AIDS (UNAIDS). Report on the global AIDS epidemic. UNAIDS, Geneva 2013.

2. Joint United Nations Programme on HIV/AIDS (UNAIDS). Global AIDS Epidemic. Facts and Figures. UNAIDS, Geneva 2012.

3. Joint United Nations Programme on HIV/AIDS (UNAIDS). Annual Report: towards universal access. UNAIDS, Geneva 2008.

4. National Agency for the Control of HIV/AIDS (NACA). Annual Progress Report: Update on the HIV/AIDS Epidemic and Response in Nigeria. NACA, Abuja 2011.

5. Joint United Nations Programme on HIV/AIDS (UNAIDS). Report on the global AIDS epidemic. UNAIDS, Geneva 2008.

6. World Health Organization (WHO). Treatment of Tuberculosis guidelines for national programmes - $3^{\text {rd }}$ Edition. WHO, Geneva 2003.

7. World Health Organization (WHO). Global Tuberculosis Control. WHO, Geneva 2011.

8. World Health Organization (WHO). Measuring Quality of Life: Division of Mental Health and Prevention of Substance Abuse. WHO, Geneva 1997.

9. Mbada CE, Onayemi O, Ogunmoyole Y, et al. Health-related quality of life and physical functioning in people living with HIV/AIDS: a case-control design. Health Qual Life Outcomes 2013; 11: 106.

10. Aggarwal AN. Health-related quality of life: A neglected aspect of pulmonary tuberculosis. Lung India 2010; 27: 1-3.

11. Phillips D. Quality of Life: Concept, Policy and Practice. $1^{\text {st }}$ ed. Routledge, London 2006.

12. Porter K, Babiker A, Bhaskaran K. Determinants of survival following HIV-1 seroconversion after the introduction of HAART. Lancet 2003; 362: 1267-1274.

13. Wig N, Lekshmi R, Pal H, et al. The impact of HIV/AIDS on the quality of life: a cross sectional study in North India. Indian J Med Sci 2006; 60 (Suppl 1): 3-12.

14. Tiwari MK, Verma S, Agrawal D, Agrawal H. Quality of life of patients with HIV infection. Indian J Soc Sci Res 2009; 6: 8.

15. Folasire OF, Irabor AE, Folasire AM. Quality of life of People living with HIV and AIDS attending the Antiretroviral Clinic, University College Hospital, Nigeria. African J Prim Heal Care Fam Med 2012; 4 (Suppl 1): 8.

16. Federal Ministry of Health (FMOH). National HIV/AIDS and Reproductive Health Survey. FMOH, Abuja 2014.

17. Deribew A, Tesfaye M, Hailmichael Y, et al. Tuberculosis and HIV co-infection: its impact on quality of life. Health Qual Life Outcomes 2009; 7: 105.

18. World Health Organization (WHO). The World Health Organization Quality of Life (WHOQOL-BREF). WHO, Geneva 2004.

19. World Health Organization (WHO). Programme on Mental Health: WHOQOL User Manual. WHO, Geneva 1998.

20. Saxena S, Carlson D, Billington R. The WHO quality of life assessment instrument (WHOQOL-Bref): the importance of its items for cross-cultural research. Qual Life Res 2001; 10 (Suppl 8): 711-721.

21. Akinpelu AO, Maruf FA, Adegoke BO. Validation of a Yoruba translation of the World Health Organization's quality of life scaleshort form among stroke survivors in Southwest Nigeria. Afr J Med Med Sci 2006; 35 (S4): 417-424.

22. Odole AC, Akinpelu AO. Validity and internal consistency of a Hausa version of the Ibadan Knee/Hip Osteoarthritis Outcome Measure. Health Qual Life Outcomes 2008; 6 (Suppl 1): 86.

23. Fatiregun A, Mofolorunsho K, Osagbemi K. Quality of Life of People Living With HIV/AIDS in Kogi State, Nigeria. Benin J Postgrad Med 2009; 11 (Suppl 1): 21-25.

24. Bello SI, Bello IK. Quality of life of HIV/AIDS patients in a secondary health care facility, Ilorin, Nigeria. Proc (Bayl Univ Med Cent) 2013; 26 (Suppl 2): 116-119.

25. Akinboro AO, Akinyemi SO, Olaitan PB, et al. Quality of life of Nigerians living with human immunodeficiency virus. Pan Afr Med J 2014; $18: 234$. 
26. Osei-Yeboah J, Owiredu W, Norgbe GK. Quality of Life of People Living with HIV/AIDS in the Ho Municipality, Ghana: A CrossSectional Study. AIDS Res Treat 2017; 2017: 6806951.

27. Giri S, Neupane M, Pant S, et al. Quality of life among people living with acquired immune deficiency syndrome receiving antiretroviral therapy: a study from Nepal. HIV AIDS Res Palliat Care 2013 5: $277-282$.

28. Odimegwu C, Akinyemi J, Alabi O. HIV-Stigma in Nigeria: Review of Research Studies, Policies, and Programmes. AIDS Res Treat 2017; 2017: 5812650

29. Tesfay A, Gebremariam A, Gerbaba M, Abrha H. Gender differences in health-related quality of life among people living with HIV on highly active antiretroviral therapy in Mekelle town, northern Ethiopia. Biomed Res Int 2015; 2015: 516369.

30. Santos E, Morandi dos C, França I, Lopes F. Quality of life of people living with HIV/AIDS in São Paulo Brazil. Revista de Saude Publica 2007; 41 (Suppl 2): 64-71.

31. Egbe CO, Dakum PS, Ekong E, et al. Depression, suicidality, and alcohol use disorder among people living with HIV/AIDS in Nigeria. BMC Public Health 2017; 17: 542 .

32. Wakawa I, Said J, Abba W, et al. The Impact of Comorbid Clinical Depression on the Health-Related Quality of Life of Adults on Highly Active Antiretroviral Therapy in Maiduguri, Northeastern Nigeria. Indian J Psychol Med 2014; 36 (Suppl 4): 408-417.

33. Akpa OM, Bamgboye EA. Correlates of the Quality of life of Adolescents in families affected by HIV/AIDS in Benue State, Nigeria. Vulnerable Child Youth Stud 2015; 10 (Suppl 3): 225-242.

34. Idler EL, Benyamini Y. Self-rated health and mortality: a review of twenty-seven community studies. J Health Soc Behav 1997; 38 21-37. 